\title{
Test Research on Influence Rule of Subsoiling Pressure to Subsoiling Quality
}

\author{
Zuo Shengjia $^{1}$, Kong Degang ${ }^{1 *}$, Liu Chunsheng ${ }^{2}$, Li Zhihui ${ }^{1}$, Zhao Yongchao ${ }^{1}$ \\ ${ }^{1}$ College of Engineering, Northeast Agricultural University, \\ Harbin 150030, China \\ ${ }^{2}$ College of mechanical, Engineering, Heilongjiang Science and Technology \\ University, Harbin 150080, China \\ zuoshengjia1984@163.com
}

\begin{abstract}
Pneumatic subsoiling is a new subsoiling technology which uses the pneumatic fracturing principle. To conduct a research on the influence rules of subsoiling pressure to subsoiling quality, the method combining the soil resistivity test and CFD simulation test will be adopted to carry out a pneumatic subsoiling test through taking the increasing rate of soil porosity and soil surface uplift as evaluation index. The test results indicate that after pneumatic subsoiling, the soil porosity of plow pan increases obviously under different subsoiling pneumatic, effective break the plow pan; with the increase of bulk density of plow pan, the spread of the high pressure gas upwards in the plow pan shows a weakening trend and its spread towards horizontal direction shows a enhancing trend; for the plow pan with larger bulk density, the increasing rate of soil porosity and soil surface uplift will increase with the increasing of subsoiling pneumatic accordingly and for the plow pan with smaller bulk density, its regularity is not obvious. Simultaneously, the subsoiling pneumatic and its technical parameters fit for plow pan with different bulk density will be obtained to provide a basis for in-depth research of pneumatic subsoiling technology and development of Pneumatic subsoiling machine.
\end{abstract}

Keywords: Pneumatic subsoiling; subsoiling pressure; bulk density of plow pan; increasing rate of soil porosity

\section{Introduction}

The implementation of subsoiling operation can break the plow pan which formed in the long-term mechanized operation, loosen the soil of plow pan, adjust the three phase ratio of soil, improve the soil porosity and water and air permeability of the soil, reduce the water and soil erosion and be beneficial to the protection for the ecological environment [1-3]. The traditional subsoiling way includes the mechanical type, that is, loosen the soil of plow pan of cultivated land with the subsoiling shovel directly. For this way, there exists subsoiling shallow depth, small affected area and other problems [4]. Currently, domestic and foreign researches on subsoiling technology mainly focus on the improvement of the subsoiling shovels and shank structures of the subsoiling machine and other aspects but few exploration and research are conducted on the subsoiling way.

Pneumatic subsoiling is a new type of subsoiling way which is different from the traditional subsoiling in principle [5]. It makes the soil to fracture and improve the soil porosity adopting the pneumatic fracturing principle to inject high pressure gas inside the soil of the cultivated land, so as to achieve the subsoiling operation of the cultivated land. Pneumatic fracturing technology was proposed by New Jersey Institute of Technology in the United States in 1988, this technology told us to inject the high pressure gas into the

* Corresponding Author 
rock and then form fracture, increase the flow channels of fluid, which can increase the permeability coefficient of the soil with low permeability [6-8]. After that, some domestic and foreign scholars proved the feasibility of pneumatic fracturing in soil, Larsson, Shen Shuilong, Liu Songyu and other scholars increased the permeability of the soil body to reinforce the soft soil foundation using the pneumatic fracturing technology [9-10], Zhang Dingwen, Han Wenjun and other scholars verified the feasibility of pneumatic fracturing in soil [11]. Kong Degang, Zuo Shengjia and other scholars verified that the subsoiling operation would have better subsoiling effect using the pneumatic fracturing principle through test [12]. Domestic and foreign had made some achievements in improving the soil permeability and other aspects using the pneumatic fracturing technology, but the domestic and foreign pneumatic fracturing technology for subsoiling operation is still at the initial stage.

This text simulates the state of soil layer and soil when conducting the subsoiling operation, analyzes and researches the influence rule of subsoiling pressure to subsoiling quality of dry cultivated land of plow pan with different bulk density, which provides a test basis for in-depth research and development of pneumatic subsoiling technology.

\section{Materials and Methods}

\subsection{Test Equipment}

Test equipment includes pneumatic subsoiling test device, testing device for soil surface uplift and other test instrument.

(1) Pneumatic subsoiling test device consists of high pressure pump, soil box and carriage, pressure regulating valve, air switch, air gun and others. See Figure 1, on its testing principle; high pressure gas generated by high pressure pump is injected inside the soil of the soil box with the air gun via pressure regulating valve, high pressure gas transmission pipe, air switch, which can make the soil porosity increase and achieve the subsoiling operation. High pressure pump can provide the maximum pressure of $3.0 \mathrm{MPa}$ and can get different subsoiling pressure through adjustment of pressure regulating valve.

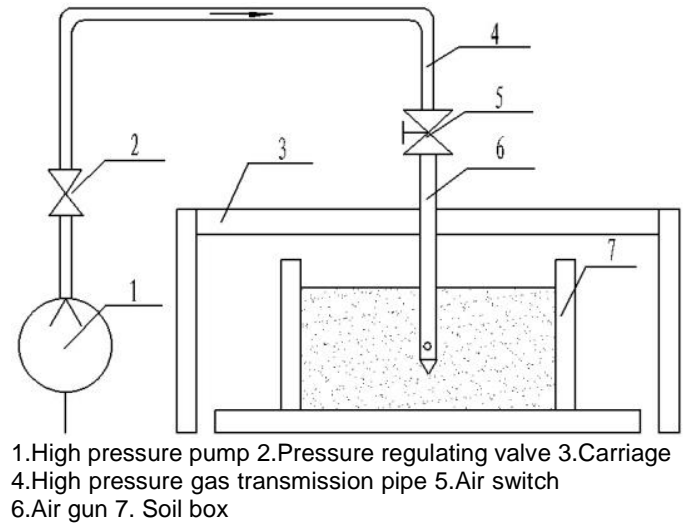

Figure 1. Schematic Diagram of Pneumatic Subsoiling Test Equipment
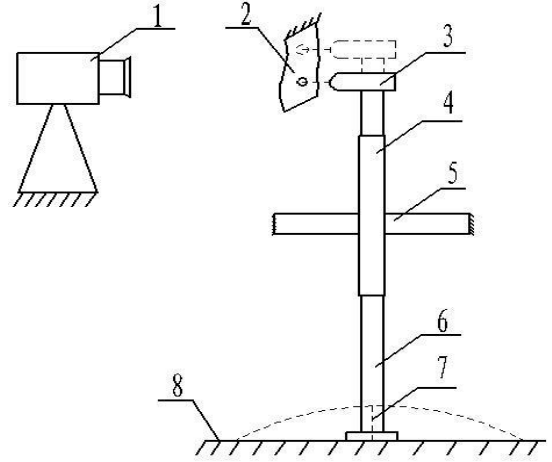

1. Video camera 2. Display 3. Emission lamp 4. Pipe run 5.Carriage 6 .Lifting column 7.Uplift capacity 8 .Soil surface

\section{Figure 2. Soil Surface Uplift} Testing Device

Air gun is made of seamless steel tube, its top end is a cone, its front end is uniformly distributed with four $\$ 5$ jet holes and its back end is connected to high pressure pump via high pressure gas transmission pipe and pressure regulating valve.

(2) We can see Figure 2, on testing device of soil surface uplift, including carriage, pipe run, lifting column, light spot display, infrared emission lamp. The lifting column slides in the pipe run, its top end is equipped with the infrared emission lamp, the light spot shines on the display; the plane of its bottom contacts with the soil surface, moving 
upward with the soil surface uplift when test, the light spot shone upon the display will move upward with it as well; simultaneously, the moving track of the light spot will be recorded by the video camera and after the completion of test, the uplift amount of the light spot will be tested by the image processing software PPC (Phantom Video camera Control Software), that is the soil surface uplift.

(3) Other test instrument includes soil resistivity tester, hardness tester, cutting ring, balance, video camera, computer and others.

\subsection{Soil for Test}

(1) The soil for test is collected from Harbin Xiangfang Farm of China .The soil test physical properties shown in Table 1, to make the moisture content of soil for test be consistent with the soil moisture content (15\% 22\%) [13] when conducting the actual subsoiling operation, the moisture content of soil for test shall be prepared to be $18 \% \quad( \pm$ $0.5 \%$ ) before test.

Table 1. The Soil Test Physical Properties

\begin{tabular}{cccc}
\hline Proportion & $\begin{array}{c}\text { density } \\
\mathrm{g} / \mathrm{cm}^{3}\end{array}$ & $\begin{array}{c}\text { dry density } \\
\mathrm{g} / \mathrm{cm}^{3}\end{array}$ & $\begin{array}{c}\text { cohesion } \\
\mathrm{kN} / \mathrm{m}^{2}\end{array}$ \\
\hline GS & $\rho$ & $\rho \mathrm{d}$ & $\mathrm{C}$ \\
2.66 & 1.39 & 1.17 & 25 \\
\hline
\end{tabular}

(2) To simulate the state of soil layer when conducting the actual subsoiling operation, the plow pan shall be arranged at the bottom of the soil box, the plow pan shall be rolled with the stone roller to make its bulk density to be $1.4 \sim 1.8 \mathrm{~g} / \mathrm{cm}^{3}$ [14-15] before test, the thickness is $0.2 \mathrm{~m}$ and the cutting-ring method [16] shall be adopted to monitor its soil bulk density during its rolling process. Then the soil for test with a thickness of about $0.2 \mathrm{~m}$ shall be laid on plow pan as the plough layer and its surface shall be made to be flat and smooth for easy to test.

\subsection{Test Method}

(1) Determine the formula for calculation of the resistivity and porosity of soil for test. Make use of soil resistivity model created by Archie [17-18]

$$
\rho_{0}=K \phi^{-m} S_{r}^{-n}
$$

In the formula: $\rho_{0}$ represents soil resistivity, $\Omega \bullet \mathrm{m} ; \phi$ represents soil porosity; $S_{r}$ represents soil saturation, $\% ; K$ represents constant coefficient related to soil characteristic.

When testing different saturation and porosity through test, the resistivity of soil for test and $m, n, \mathrm{~K}$ in the formula (1) shall be determined through regression analysis. The formula for calculation of its resistivity and porosity shall be determined

$$
\rho_{0}=0.102 \phi^{-5.006}\left[2.65 W \frac{(1-\phi)}{\phi}\right]^{-3.678}
$$

In the formula: $\rho_{0}$ represents soil resistivity, $\Omega \bullet \mathrm{m} ; W$ represents soil moisture content; $\phi$ represents soil porosity. Correlation coefficient $R^{2}$ is 0.96 .

(2) Test the soil resistivity at test points before conducting the pneumatic subsoiling operation. The soil resistivity tester shall be used to test the soil resistivity at each test point through Wenner Method [19-20]. When testing, the air gun shall be inserted into the 
plow pan at the center of soil surface, making jet holes $0.35 \mathrm{~m}$ distance from the soil surface and air gun shall be fixed on the carriage. See Figure 3, on location distribution at test points. In the figure, $x$ and $y$ represent the horizontal distance from the center of soil surface (hereinafter referred to as horizontal distance), $P$ represents each test point and the value in parentheses represents the depth at each test point.

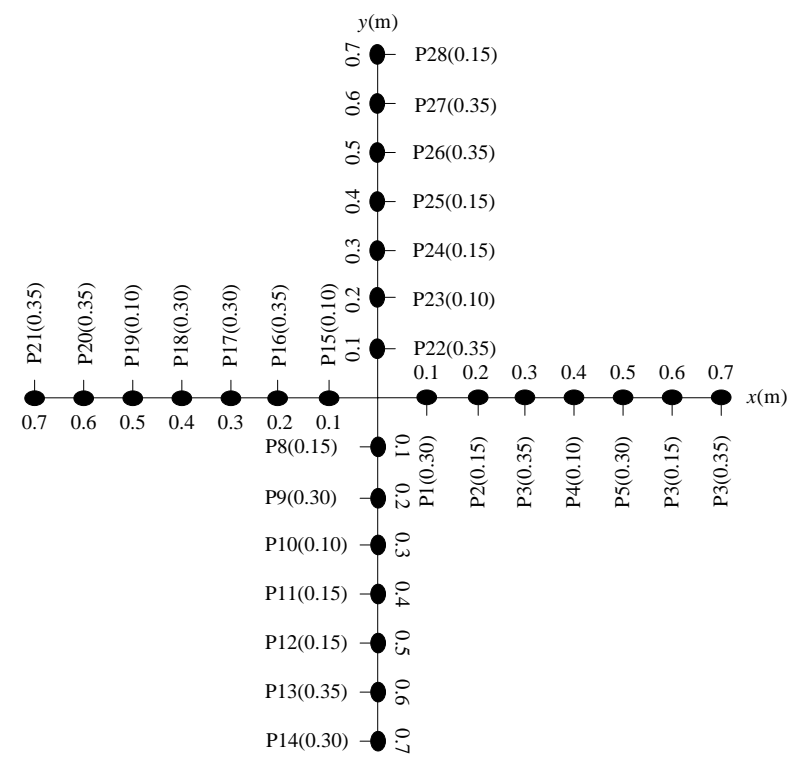

Figure 3. Distribution Map of Position Coordinates of Resistivity at Test Point

(3) Keep a record of initial height of soil surface. The equal spacing of height of soil surface at test points is set on $\mathrm{x}$ and $\mathrm{y}$ axis shown in Figure 3, that 6 test points shall be set on every half axis and its starting point and ending point respectively are $0.05 \mathrm{~m}$ and $0.55 \mathrm{~m}$. The video camera shall be installed in the vertical $\mathrm{x}$ and $\mathrm{y}$ direction simultaneously so as to keep a record of initial height of light spot on spot display.

(4) Test. Conduct a pneumatic subsoiling test respectively for each combination according to the full combination of two factors and three levels shown in Table 2, after the completion of test, the results shall be recorded by video camera and imported into the computer to measure the soil surface uplift; meanwhile, the soil resistivity tester shall be used to test the soil resistivity at each test point and the soil porosity at test points before and after subsoiling operation shall be obtained using the formula (2). Each combination shall be repeated three times and the average value of results at all test points shall be taken as the final value.

Table 2. Test Factor Level Table

\begin{tabular}{ccc}
\hline \multirow{2}{*}{ Level } & \multicolumn{3}{c}{ Factor } \\
\cline { 2 - 3 } & Subsoiling pressure $(\mathrm{MPa})$ & plow pan bulk density $\left(\mathrm{g} / \mathrm{cm}^{3}\right)$ \\
\hline 1 & 1.4 & 1.4 \\
2 & 1.8 & 1.6 \\
3 & 2.2 & 1.8 \\
\hline
\end{tabular}

(5) Simulation test. Computational fluid dynamics (CFD) and Discrete Element Method (DEM) have been widely applied to agricultural engineering and many other field in recent years [21-22]. During the process of conducting a pneumatic subsoiling test for 
soil, the soil can be considered as a porous medium which is formed by the dense packing of granules according to certain porosity; air flow passes through the soil with certain pressure via puff port and the change of the gas content in soil leads to the change of the soil porosity. As a result, the density distribution of the gas in soil can reflect the change situation of the soil porosity directly. This text conducts a calculation for solution using CFD software and porous medium module as well as through the establishment of geometrical model, mesh generation and boundary condition setting. When the simulated test conditions are consistent with the pneumatic subsoiling test, the density distribution map of gas inside the plow pan under three states that the pressure at puff port is $1.8 \mathrm{MPa}$ (the average subsoiling pressure during test), the bulk density of plow pan is 1.4 (the porosity is 0.3 ), 1.6 (the porosity is 0.4 ) and 1.8 (the porosity is 0.5 ) $\mathrm{g} / \mathrm{cm}^{3}$.

\section{Results and Discussion}

The pneumatic subsoiling operation can increase the air content in soil, lead to the increase of the soil porosity and soil volume expansion and increase of soil surface uplift simultaneously. It can be said that the increasing rate of the soil porosity (the percentage between the difference of the soil porosity before and after test and the soil porosity ratio before test) and the soil surface uplift reflect the soil loosening situation of soil from the aspects of the interior and surface of soil respectively. As a result, this text carries out a research on influence rule of subsoiling pressure to subsoiling quality through taking increasing rate of porosity and soil surface uplift as index and analyzing the changes of increasing rate of the soil porosity of plow pan and soil surface uplift with different bulk density under different subsoiling pressure.

See Figure 4, 5 and 6, on change rule of the increasing rate of the soil porosity of plow pan and soil surface uplift with the change of the horizontal distance which is determined according to the test data concluded under different subsoiling pressure and under the conditions of plow pan with different bulk density. To facilitate the analysis and discussion, insert the density distribution maps of high pressure gas in the plow pan with the same bulk density concluded from the simulation test into its corresponding figures.

\subsection{Influences on Plow Pan with Bulk Density of $1.4 \mathrm{~g} / \mathrm{cm}^{3}$}

It can be seen from Figure $4 \mathrm{a}$, that for the plow pan with bulk density of $1.4 \mathrm{~g} / \mathrm{cm}^{3}$, the porosity increasing rate caused by the subsoiling pressure of 1.4, 1.8 and 2.2 Mpa shall increase gradually within a horizontal distance of $0.3 \mathrm{~m}$ or less than $0.4 \mathrm{~m}$, reaches peak value at a horizontal distance of $0.3 \mathrm{~m}$ or $0.4 \mathrm{~m}$, decreases rapidly and is reduced to be 0 at a horizontal distance of $0.7 \mathrm{~m}$; It can be seen from Figure $4 \mathrm{~b}$, that the soil surface uplift shall show a descending trend with the increase of the horizontal distance and it shall reach the minimum value of 0 at a horizontal distance of $0.45 \mathrm{~m}$. This is because that after the high pressure gas (the part marked yellow and green color in Figure 4c, shall not be indicated any longer in the following contents) blowing out from the jet holes, when the gas moving towards the horizontal direction, the gas shall spread around and its pressure shall decrease gradually. Based on the density distribution (see Figure 4c), of high pressure gas in soil, it can be divided into three areas of proximal influenced area (the horizontal distance is less than $0.2 \mathrm{~m}$ part), mainly-influenced area (the horizontal distance is $0.2-0.35 \mathrm{~m}$, part in red circle) and distal influenced area (the horizontal distance is $0.35 \sim 0.7 \mathrm{~m}$ part). In proximal influenced area, as the gas content in soil is relatively less, the porosity increasing rate is relatively not large (see Figure $4 \mathrm{a}$ ), in addition, the high pressure gas spreads to spherical surface around through taking the jet point as a center and forms the pressure field [23]. As there is no constraint above the soil box, the resultant force above the pressure field makes the soil surface above the soil box uplift and forms a shape of ball coronary, which means the more close to the center of the soil surface, the larger of the soil surface uplift (see Figure $4 \mathrm{~b}$ ). In mainly-influenced area, as 
the gas content in soil in this area is more, it makes the porosity increasing rate to be largest (see Figure 4a). But as the cohesion of the plow pan with bulk density of $1.4 \mathrm{~g} / \mathrm{cm}^{3}$ is relatively smaller, the high pressure gas is easy to spread and crack in the plow pan, most of the high pressure gas shall be leaked out from the soil surface, which results in that the pressure and gas content in soil decrease. So after that the porosity increasing rate decreases rapidly and the soil surface uplift is also reduced to be 0 at a horizontal distance of $0.45 \mathrm{~m}$ (see Figure 4b). In distal influenced area (see Figure 4c), as the air flow path is longer, the penetrating power of high pressure gas has been weakened obviously and the gas content is lower, the soil surface uplift has shown no numerical value and the increase of the porosity increasing rate is lower than that of proximal influenced area obviously; the porosity increasing rate is 0 at a horizontal distance of $0.7 \mathrm{~m}$.

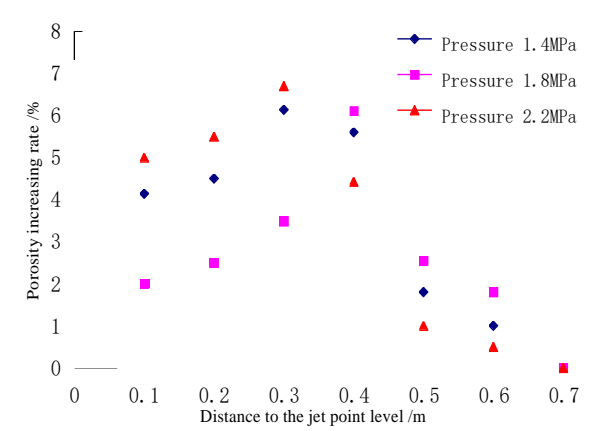

a. Porosity Increasing Rate

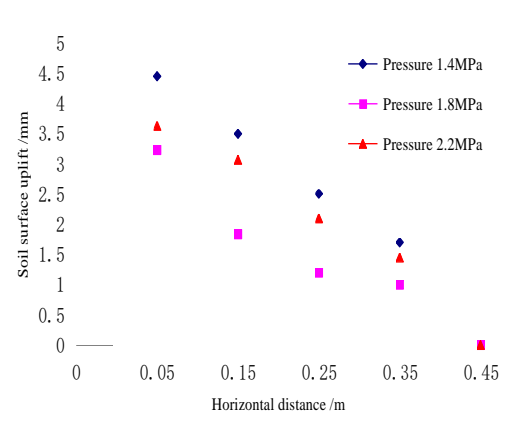

b. Soil Surface Uplift

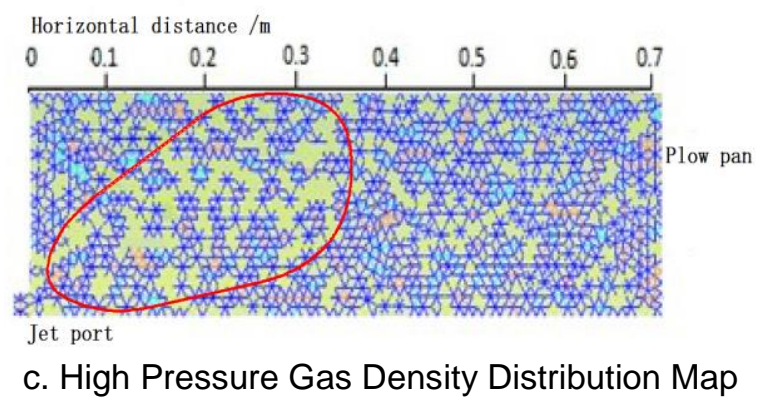

\section{Figure 4. Porosity Increasing Rate and Soil Surface Uplift (Bulk Density $1.4 \mathrm{~g} / \mathrm{cm}^{3}$ )}

It can be seen from Figure $4 a$, and $4 b$, that the porosity increasing rate and soil surface uplift does not increase with the increasing of the subsoiling pressure, such as, when the horizontal distance is within the range of less than $0.3 \mathrm{~m}$, the porosity increasing rates caused by the subsoiling pressure of 1.4 and $2.2 \mathrm{Mpa}$ are obviously more than that caused by the subsoiling pressure of $1.8 \mathrm{Mpa}(\mathrm{p}<0.01)$; but when the horizontal distance is within the range of more than $0.4 \mathrm{~m}$, the porosity increasing rates caused by the subsoiling pressure of $1.8 \mathrm{Mpa}$ are obviously more than that caused by the subsoiling pressure of 1.4 and $2.2 \mathrm{Mpa}(\mathrm{p}<0.01)$. When the horizontal distance is within the range of $0.45 \mathrm{~m}$, the soil surface uplift reaches the maximum value when the subsoiling pressure is $1.4 \mathrm{Mpa}$, ranks second when the subsoiling pressure is $2.2 \mathrm{Mpa}$ and reaches the minimum value when the subsoiling pressure is $1.6 \mathrm{Mpa}$, which means the regularity of porosity increasing rate and soil surface uplift changing with the subsoiling pressure is not obvious. This is because that the soil compaction in the plow pan with bulk density of $1.4 \mathrm{~g} / \mathrm{cm}^{3}$ is not large, easy to crack and leak and be affected by other random factors, which can make the porosity increasing rate and soil surface uplift show a irregular change with the increase of the subsoiling pressure. 


\subsection{Influences on Plow Pan with Bulk Density of $1.6 \mathrm{~g} / \mathrm{cm}^{3}$}

It can be seen from Figure 5a that, for the plow pan with bulk density of $1.6 \mathrm{~g} / \mathrm{cm}^{3}$, the porosity increasing rate under different subsoiling pressure shall slightly decrease with the increase of the horizontal distance when the horizontal distance is less than $0.3 \mathrm{~m}$, increase at a horizontal distance of $0.3 \mathrm{~m}$, reach peak value at a horizontal distance of $0.4 \mathrm{~m}$ and then decrease with the increase of the horizontal distance and reduce to be 0 at a horizontal distance of $0.7 \mathrm{~m}$; it can be seen from Figure $5 \mathrm{~b}$, that, the soil surface uplift under different subsoiling pressure decreases gradually with the increase of the horizontal distance and shall be reduced to be 0 when at a horizontal distance of $0.45 \mathrm{~m}$.

Similar to the above-mentioned analysis in article 3.1, after blowing out from the jet holes, the high pressure gas shall form three areas similar to that in Figure 4c, but its position is slightly lagged behind. In proximal influenced area with a horizontal distance less than $0.3 \mathrm{~m}$ (see Figure $5 \mathrm{c}$ ), as its pressure is lower and the high pressure gas is relatively not easy to enter the soil and the gas content is lower, the porosity increasing rate shall change very little (see Figure 5a). Similarly, the soil surface uplift produced by the resultant force of pressure field forms a shape of ball coronary similar to that of the soil with bulk density of $1.4 \mathrm{~g} / \mathrm{cm}^{3}$, that is, the soil surface uplift reaches the maximum value around the jet points and shows a descending trend which approximates to the circular curve law after keeping away from the jet points (see Figure 5b). As the cohesion of plow pan with bulk density of $1.4 \mathrm{~g} / \mathrm{cm}^{3}$ is relatively larger, the air flow is relatively not easy to spread upward but the trend of spreading towards the horizontal direction is enhanced, which makes its mainly-influenced area with the relative bulk density of $1.4 \mathrm{~g} / \mathrm{cm}^{3}$ move backward to the horizontal distance of $0.4 \mathrm{~m}$ (the part marked red circle in Figure 5c). As the gas content in this area is relatively more, it makes the porosity increasing rate reach the maximum value (see Figure 5a). In distal influenced area with a horizontal distance more than $0.45 \mathrm{~m}$ (see Figure $5 \mathrm{c}$ ), as part of high pressure gases are leaked out from the soil surface, resulting in the diffusive force of high pressure gases in soil weakens and the gas content decreases, the porosity increasing rate in this area drops gradually and drops to 0 at a horizontal distance of $0.7 \mathrm{~m}$ (see Figure $5 \mathrm{a}$ ). The soil surface uplift is reduced gradually and is showed no numerical value when the horizontal distance reaches $0.45 \mathrm{~m}$.

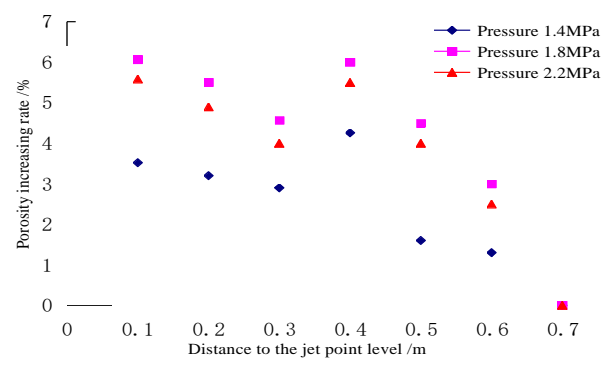

a. Porosity Increasing Rate

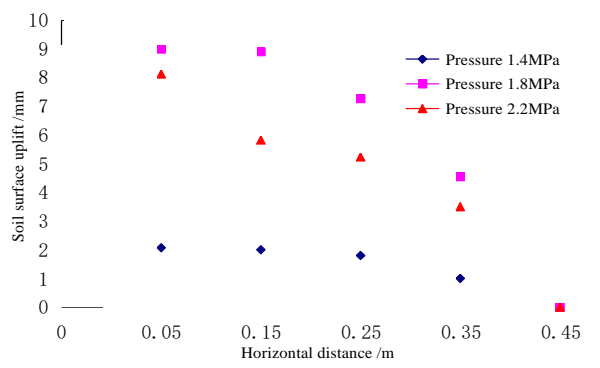

b. Soil Surface Uplift

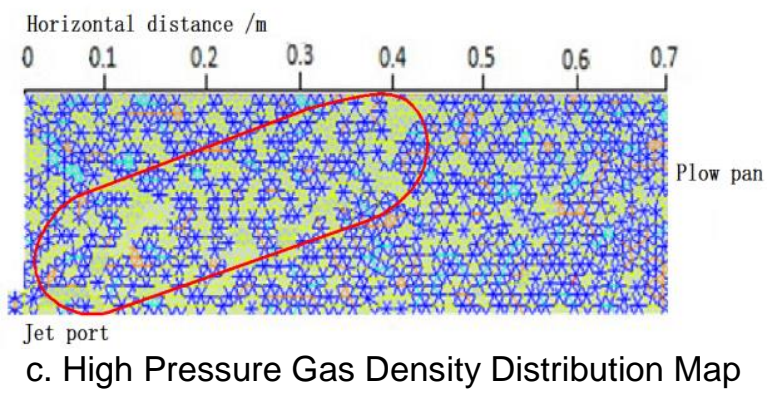

Figure 5. Porosity Increasing Rate and Soil Surface Uplift (Bulk Density $1.6 \mathrm{~g} / \mathrm{cm}^{3}$ ) 
It can also be seen from the Figure 5a, and 5b, that, for the porosity increasing rate and the soil surface uplift of the same horizontal distance within $0.7 \mathrm{~m}$, that of $1.8 \mathrm{MPa}$ are the largest, that of $2.2 \mathrm{MPa}$ come second, that of $1.4 \mathrm{MPa}$ are the smallest ( $<<0.01)$. This is because when the soil bulk density is $1.6 \mathrm{~g} / \mathrm{cm}^{3}$ and soil density of the plow pan is intermediate with a subsoiling pressure of $1.4 \mathrm{MPa}$, there is little gas leakage. However, due to the low air pressure of itself, little gas content is escaped into the soil. So the porosity increasing rate and the soil surface uplift are the lowest (See Figure 5a, and 5b). When the subsoiling pressure is as high as $1.8 \mathrm{MPa}$, high-pressure gas has the increasing trend of horizontal diffusion and decreasing uplifting force of upward diffusion, which may cause less leakage. So that there is more gas content remained in the soil. So its porosity increasing rate and soil surface uplift are the largest. And when the subsoiling pressure is $2.2 \mathrm{MPa}$, the trend of horizontal diffusion of high-pressure gas further increases compared with that of $1.8 \mathrm{MPa}$, while the uplifting force caused by air pressure also increases. It is easy to overcome the pressure of the above soil and cause gas leakage, which results in reduction of gas content in the soil of plow pan. So its porosity increase rate and soil surface uplift are less than that of $1.8 \mathrm{MPa}$.

\subsection{Influence On Plow Pan of the Bulk Density of $1.8 \mathrm{~g} / \mathrm{cm}^{3}$}

It can be seen form Figure $6 \mathrm{a}$ that when the bulk density of plow pan is $1.8 \mathrm{~g} / \mathrm{cm}^{3}$, the porosity increase rate caused by subsoiling pressure slowly drops with the increase of horizontal distance. It drops to 0 when the horizontal distance is $0.7 \mathrm{~m}$; it can be seen form figure $6 \mathrm{a}$ that the soil surface uplift shows a diminishing trend with the increase of horizontal distance and it is reduced to 0 at the points where the horizontal distances are 0.45 and $0.55 \mathrm{~m}$. A number of research results show that the spreading directions of the fractures in pneumatic fracturing are perpendicular to the direction of minimum principal stress. For pneumatic fracturing of shallow soil, its minimum principal stress shall be vertical and the fractures shall be horizontal [24]. Pneumatic subsoiling is pneumatic fracturing of shallow soil. Its minimum principal stress shall be vertical. When the bulk density of plow pan is $1.8 \mathrm{~g} / \mathrm{cm}^{3}$, its resultant of vertical principal stresses shall be greater than that of the bulk densities of 1.4 and $1.6 \mathrm{~g} / \mathrm{cm}^{3}$. High-pressure gas is much easier to cause horizontal fractures. That is airflow is much easier to diffuse horizontally. After high-pressure gas blows out (See Figure 6c), most of the high-pressure gas moves along the horizontal direction and uniformly distributes in the plow pan, which makes the boundaries between the proximal influenced area, mainly-influenced area and distal influenced area are not obvious. There is little difference among gas content of all the domains. The porosity increasing rate changes a little relative to that of the bulk densities of plow pans of 1.4 and $1.6 \mathrm{~g} / \mathrm{cm}^{3}$ (See Figure $4 \mathrm{a}, 5 \mathrm{a}$ ). In the same way, the influence domain and the maximum value of the soil surface uplift caused by the pressure field is larger than that of the bulk densities of plow pans of 1.4 and $1.6 \mathrm{~g} / \mathrm{cm}^{3}$ (See Figure $4 \mathrm{~b}$, 5b). Similar to the above analysis in Section 3.2, with the increase of the horizontal distance, due to the weakened diffusion capacity of the high-pressure gas, the porosity increasing rate is reduced to 0 at the point where the horizontal distance is $0.7 \mathrm{~m}$. In addition, it can be seen that the porosity increasing rate, the soil surface uplift and the influence domain caused by small subsoiling pressure (1.4MPa) is significantly smaller (See Figure 6a, Figure 6b). This shows that greater subsoiling pressure is suitable for plow pan of greater bulk density. 


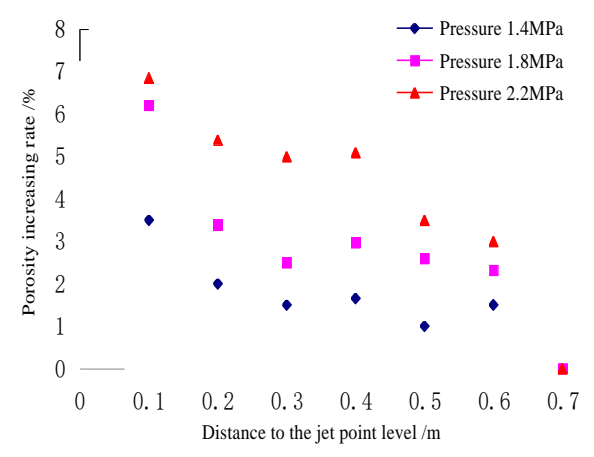

a. Porosity Increasing Rate

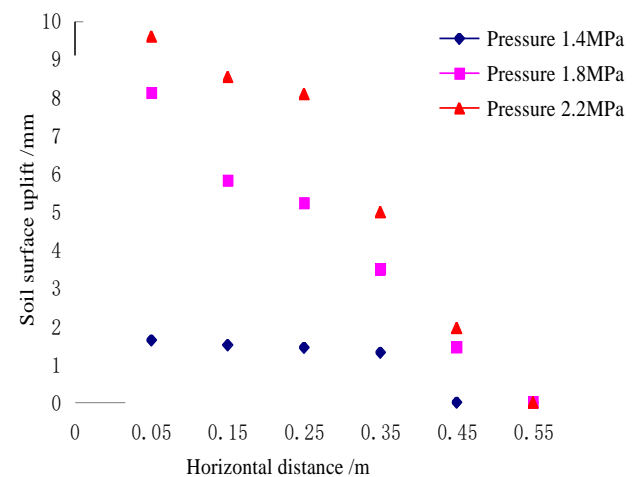

b. Soil Surface Uplift

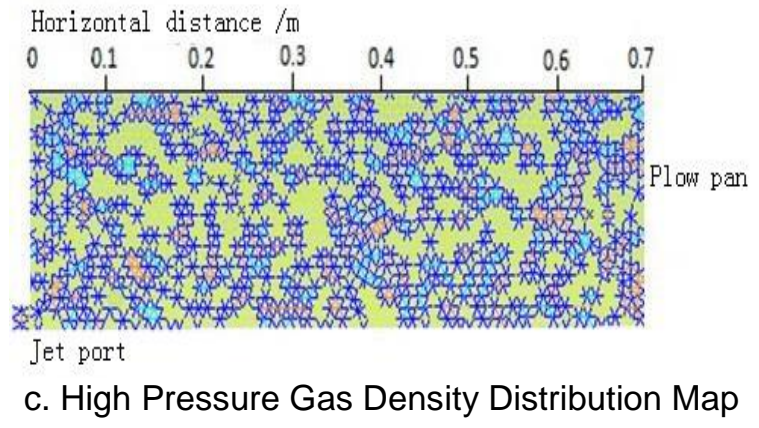

Figure 7. Porosity Increasing Rate and Soil Surface Uplift (Bulk Density $1.8 \mathrm{~g} / \mathrm{cm}^{3}$ )

It can be seen from the Figure $6 a$, and $6 \mathrm{~b}$, the porosity increasing rate and the soil surface uplift increases with the increase of the air pressure. For example, for the porosity increasing rate and the soil surface uplift of the same horizontal distance within $0.7 \mathrm{~m}$, that of $2.2 \mathrm{MPa}$ are the largest, that of $1.8 \mathrm{MPa}$ come second, that of $1.4 \mathrm{MPa}$ are the smallest $(p<0.01)$. This is because for plow pan of the soil bulk density of $1.8 \mathrm{~g} / \mathrm{cm}^{3}$, its soil density and soil cohesion are large. High-pressure gas is difficult to diffuse upwards and cause leakage. The greater subsoiling pressure is the greater the porosity increasing rate and soil surface uplift of the plow pan .

Based on the above analysis, we can know that for plow pan of low bulk density, high-pressure gas is not easy to diffuse horizontally. With the increase of bulk density, the trend of horizontal diffusion of high-pressure gas increases gradually. The influence of subsoiling pressure on the porosity increasing rate and the soil surface uplift also becomes stronger. When bulk density of the plow pan is $1.4 \mathrm{~g} / \mathrm{cm}^{3}$, there is no apparent rule for the influence of subsoiling pressure on the porosity increasing rate and the soil surface uplift; when bulk density of the plow pan is $1.6 \mathrm{~g} / \mathrm{cm}^{3}$, influence of subsoiling pressure on the porosity increasing rate and the soil surface uplift appears gradually; when bulk density of the plow pan is $1.8 \mathrm{~g} / \mathrm{cm}^{3}$, there is apparent influence of subsoiling pressure on the porosity increasing rate and the soil surface uplift, which increases correspondingly with the increase of air pressure.

\section{Conclusions}

(1) After pneumatic subsoiling, the soil porosity of the plow pan increases significantly, effective break the plow pan.

(2) For plow pans with smaller bulk density, high-pressure gas is easy to diffuse and cause leakage. There is no apparent rule that the porosity increasing rate and the soil surface uplift change with air pressure changes; for plow pans with greater bulk density, high-pressure gas is easy to diffuse horizontally. The porosity increasing rate and the soil 
surface uplift increase correspondingly with the increase of air pressure.

(3)The interaction between the soil bulk density of the plow pan and the subsoiling pressure has significant influence on the porosity increasing rate and the soil surface uplift. For plow pans with the bulk density of $1.4,1.6$ and $1.8 \mathrm{~g} / \mathrm{cm}^{3}$, subsoiling pressures of $1.4,1.8$ and $2.2 \mathrm{Mpa}$ shall be respectively selected to obtain good subsoiling quality.

\section{Acknowledgments}

The authors would like to acknowledge the financial support from the Science and Technology Support subject of China (2014BAD06B04); the National Natural Science Foundation of China (31272130); Man-Machine Engineering Research of Northeast Agricultural University.

\section{References}

[1] L. Hongwen, C. Junda and L. Wenying, "Study onsubsoiling technique for conservation tillage field" Transactions of the Chinese Society of Agricultural Machinery, vol. 31, no. 6, (2000), pp. 42-45.

[2] Z. Fengwu, W. Jingli and P. Shiqiang, "Advances in researches of soil subsoiling technique", Journal of Jilin Agricultural University, vol. 25, no. 4, (2003), pp. 57-61.

[3] Z. Ruifu, Y. Hengshan and G. Julin, "Effect of subsoiling on root morphological and physiological characteristics of spring maize", Transactions of the Chinese Society of Agricultural Engineering(Transactions of the CSAE), vol. 31, no. 5, (2015), pp. 78-84.

[4] L. Xia, F. Junfeng and Z. Dongxing, "Experiment analysis on traction resistance of vibration subsoiler" Transactions of the CSAE, vol. 28, no. 1, (2012), pp. 32-36.

[5] K. Degang, "A air-pressure type subsoiling machine", Chinese Patent:201420516606.6,2014-11-24, (2015).

[6] S. L. Shen, N. Miura and H. Koga, "Interaction mechanism between deep mixing column and surrounding clay during installation”, Canadian Geotechnical Journal, vol. 40, no. 2, (2003), pp. 293-307.

[7] S. Larsson, M. Dahlstrom and B. Nilsson, "Uniformity of lime-cement columns for deep mixing: afield study", Ground Improvement, vol. 9, no. 1, (2005), pp. 1-15.

[8] S. N. Venkatraman, J. R. Schuring and T. M. Boland, "Application of pneumatic fracturing to enhance in situ bioremediation", Journal of Soil Contamination, vol. 7, no. 2, (1998), pp. 43-162.

[9] D. Yuan, J. R. Schuring and P C. Chan, "Volatile contaminant extraction enhanced by pneumatic fracturing”, Practice Periodical of Hazardous, Toxic, and Radioactive Waste Management, vol. 3, no. 2, (1999), pp. 69-76.

[10] H. Wenjun, L. Songyu and Z. Dingwen, "Characteristics and influencing factors analysis of propagation of pneumatic fracturing in soils", China Civil Engineering Journal, vol. 44, no. 9, (2011), pp. 87-97.

[11] H. Wenjun, L. Songyu and Z. Dingwen, "Effect analysis of a soft ground reinforced bya combined vacuum", China Civil Engineering Journal, vol. 33, no. 5, (2012), pp. 1467-1474.

[12] Z. Shngjia, K. Denggang and L. Liyi, "Experiment on effect of air-pressure subsoiling based on air-pressure cracking theory", Transactions of the CSAE,vol. 32, no. 1, (2016), pp. 54-60.

[13] L. Dongshan, "The key points for the implementation of mechanized deep loosening Technology" Agricultural Science \& Technology and Equipment, vol. 220, no. 10, (2012), pp. 18-21.

[14] S. Yiwen, "Soil Mechanics Agriculture", China Agriculture Press, Beijing, (2000).

[15] Z. Ruifu, Y. Hengshan and G. Julin, "Effect of subsoiling on root morphological and physiological characteristics of spring maize", Transactions of theChinese Society of Agricultural Engineering (Transactions of the CSAE), vol. 31, no. 5, (2015), pp. 78-84.

[16] CAS Nanjing Institute of Soil Soil physical research room.Determination of soil physical properties, China Science Press, Beijing, (1978).

[17] L. Ying, G. Xiaonan and G. Biao, "Research on Conductivity Characteristics of Soft Clay During Electro-osmosis and Its Conductive Mechanism", Chinese Journal of Rock Mechanics and Engineering, vol. 26, no. 1, (2004), pp. 83-87.

[18] L. Guohua, W. Zhengyu and H. Jianping, "Research on electrical resistivity feature of soil and it's application", Chinese Journal of Geotechnical Engineering, vol. 26, no. 1, (2004), pp. 83-87.

[19] L. Liangfu, "Soil Electricale", Meteorological Press, Beijing, (2008).

[20] L. Shengdong and W. Rongxin, "High density electric resistance method applied to monitor and measure overburden failure above seam", Coal Science and Technology, vol. 29, no. 4, (2001), pp. 18-21.

[21] L. Liyi and H. Shiyang, "Numerical Simulation and Experiment on Paddy Ventilation Resistance Based on CFD-DEM", Transactions of the Chinese Society of Agricultural Machinery, vol. 46, no. 8, (2015), pp. 27-32.

[22] W. Guoqiang and H. Wanjun, "Discrete element method and practice of the EDEM", Northwestern 
Polytechnical University Press, Xi'an, (2010).

[23] H. Wenjun, L. Songyu, Z.Dingwen and G. Chenyin, "Numerical simulation of pressure-controlled cavity expansion. Rock and Soil Mechanics", vol. 1, no. 1, (2010), pp. 405-410.

[24] L. C. Murdoch, "Mechanical analysis of idealized shallow hydraulic fracture", Journal of Geotechnical and Geoenvironmental Engineering, vol. 128, no. 6, (2002), pp. 488-495.

\section{Author}

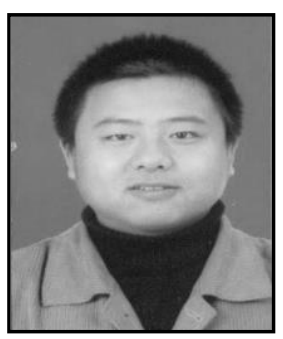

Zuo Shengjia (1984-), male, born in Tonghua, Jilin Province, China. He is a Ph.D. student in the college of Engineering at Northeast Agricultural University. His research direction is Agricultural Mechanization Engineering. 
International Journal of $u$ - and e- Service, Science and Technology Vol.9, No. 10 (2016) 